INFLAMMATORY BOWEL DISEASE

\title{
5-Aminosalicylate use and colorectal cancer risk in inflammatory bowel disease: a large epidemiological study
}

\author{
T P van Staa, T Card, R F Logan, H G M Leufkens
}

See end of article for authors' affiliations

Correspondence to: Professor R F Logan, Division of Epidemiology and Public Health, School of Community Health Sciences, University of Nottingham Medical School, Nottingham NG7 $2 \mathrm{UH}$, UK; richard.logan@ nottingham.ac.uk

Revised version received 14 June 2005

Accepted for publication 17 June 2005

Published online first 30 June 2005
Background and aims: The objective of this study was to evaluate the risk of colorectal cancer (CRC) in patients taking aminosalicylates (5-ASA) for inflammatory bowel disease (IBD).

Methods: The General Practice Research Database (GPRD) which contains the primary care records of five million people in the UK was used to identify users of mesalazine, balsalazide, olsalazine, or sulfasalazine with a history of IBD. In a nested case control analysis, each incident CRC case with any use of a 5-ASA in the six months before the CRC diagnosis was matched by age, sex, and calendar time to six control patients who were also currently using a 5-ASA. Patients were then classified according to regularity of use. The analysis was controlled for body mass index, IBD duration, history of colorectal polyps, use of non-steroidal anti-inflammatory drugs, paracetamol, aspirin, immunosuppressants, oral and rectal glucocorticoids, prior gastrointestinal hospitalisation, recorded colonoscopy, and number of visits to the general practitioner for IBD symptoms in the 6-24 months before diagnosis.

Results: The study population included 18969 patients, of whom 100 had developed CRC during 5-ASA exposure. Most of these cases had a history of ulcerative colitis (76 patients). In the case control analysis, regular users, defined as having six or more 5-ASA prescriptions in the previous 12 months, were found to have a decreased risk of CRC compared with irregular users (crude odds ratio (OR) 0.7 (0.44-1.03); adjusted OR $0.60(0.38-0.96))$. Regular users of sulfasalazine with 6-12 prescriptions before had an adjusted OR of $0.95(0.22-4.11)$; with 13-30 prior prescriptions this was $0.41(0.14-1.20)$ and with $>30$ prior prescriptions this was $0.77(0.37-1.60)$. For mesalazine users, these values were $1.13(0.49-$ $2.59), 0.30(0.11-0.83)$, and $0.31(0.11-0.84)$, respectively.

Conclusion: These results show that regular 5-ASA use is associated with some reduction in the risk of CRC developing in ulcerative colitis.

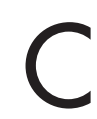
olorectal cancer (CRC) is one of the most feared complications of inflammatory bowel disease (IBD). A recent meta-analysis estimated that one in five patients with ulcerative colitis (UC) will develop CRC over 30 years, with the risk of CRC being greatest in patients with extensive UC of long duration. ${ }^{1}$ Patients with Crohn's disease (CD) also have an increased risk of CRC, with one large epidemiological study finding similar rates of CRC between UC and CD patients. $^{2}$

5-Aminosalicylic acids (5-ASA), including sulfasalazine and mesalazine, are the most commonly prescribed antiinflammatory drugs in IBD. Regular 5-ASA intake may reduce the risk of CRC. ${ }^{3-5}$ Two case control studies have found lower risks of CRC in patients on regular 5-ASA therapy ${ }^{6} 7$ and two small cohort studies of UC patients have suggested that regular salazapyrin users had a lower CRC risk. ${ }^{8}$ Furthermore, two prospective studies have reported positive effects of 5-ASA therapy on surrogate markers of CRC, such as rectal cell proliferation and apoptotic index. ${ }^{10}{ }^{11}$ However, the two most recent studies, using a case control design similar to earlier studies, have found no reduction in CRC risk in regular 5-ASA users. ${ }^{12} 13$ The aim of the present study was to assess whether regular 5-ASA therapy reduces the risk of CRC in a large database with prospective recording of drug prescribing. As any effect of 5-ASA therapy on the risk of CRC could be mediated by the reduction in mucosal inflammation, we also investigated the possible effects on CRC risk of regular use of oral glucocorticoids or immunosuppressants. ${ }^{3}$

\section{METHODS}

\section{Data source}

In the UK, health care delivery is centred on general practitioners whose responsibilities include primary health care and specialist referrals. The information for this study was obtained from the General Practice Research Database (GPRD) which consists of computerised medical records of general practices across the UK. ${ }^{14}$ Approximately $6 \%$ of the total registered population of England and Wales is represented in the database and it includes a cumulative total of over five million adult patients. The age and sex distribution of patients enrolled is representative of the general English and Welsh populations. The data accrued in the GPRD include demographic information (including patient's sex and year of birth), prescription details, clinical events, preventive care, referrals to specialist care, and hospital admissions and their major outcomes. The data quality of each entry into GPRD is measured against specific targets, developed by comparisons with external statistics, to ensure that research standards are met. Only data from practices that meet this quality control are compiled to form the GPRD database. Data collection for the GPRD began in 1987 and, for

Abbreviations: 5-ASA, 5-aminosalicylate; CRC, colorectal cancer; NSAIDs, non-steroidal anti-inflammatory drugs; IBD, inflammatory bowel disease; UC, ulcerative colitis; CD, Crohn's disease; GPRD, General Practice Research Database; OR, odds ratio; RR, relative rate; $R A$, rheumatoid arthritis 
this study, ended in 2001. A high level of data validity of GPRD has been reported both generally as well as for IBD specifically. ${ }^{15-17}$

\section{Study population}

We screened the GPRD for all permanently registered adults aged 18 years or older who were prescribed a 5-ASA formulation. The 5-ASA drugs included balsalazide sodium, mesalazine, olsalazine sodium, and sulfasalazine. The approved indications in the UK for balsalazide sodium, mesalazine, and olsalazine sodium are treatment of mild to moderate UC and maintenance of remission; for sulfasalazine, these are treatment of mild to moderate UC, maintenance of remission, active CD and, also, active rheumatoid arthritis (RA). ${ }^{18}$ Given these different indications, patients who only used sulfasalazine were classified according to the presence or absence of IBD in the medical records. The study cohort was divided into two groups. The first group, referred to as "5-ASA/IBD" , included either patients who received a prescription during the period of data collection for balsalazide, mesalazine, or olsalazine, or who received sulfasalazine and who had a record indicating the presence of IBD. The second group ("sulfasalazine RA") included the remaining sulfasalazine users. A reference group was selected consisting of patients without a history of IBD or prescription for 5-ASA. Each patient from the two 5-ASA groups was matched to a reference patient by age (within five years), sex, and medical practice. They were also matched by calendar time (that is, they had to be registered at the practice at the date of the first record of a 5-ASA prescription of their matched patient). In the event of no eligible control patient within five years of age, an age and sex matched control patient was selected from another practice.

The study patients were followed for the occurrence of CRC (that is, malignant cancer of the colon (International Classification of Diseases 9th Revision 153), malignant cancer of the rectum (154.0, 154.1), and gastrointestinal carcinoma (159.0)). Patients with a recurrent event (that is, history of CRC prior to the first 5-ASA during the period of GPRD data collection) were excluded.

\section{Cohort analysis}

In the cohort analysis, rates of CRC during follow up were estimated by dividing the number of cases by the total number of person years of follow up. 5-ASA users were followed from the first 5-ASA prescription during the period of data collection up to the end of data collection.

\section{Nested case control analysis}

A nested case control analysis was used to evaluate the effect of the dynamics of 5-ASA use on the risk of CRC. This analysis was conducted in the "5-ASA/IBD" group and was restricted to current 5-ASA users (that is, those who were prescribed a 5-ASA drug in the six months preceding the case's index date). This was done in order to match cases and controls as far as possible with available data on IBD activity. CRC cases were patients in the 5-ASA IBD cohort who experienced a first CRC event during follow up and who were current users of 5-ASA. The date of the CRC diagnosis was the index date. For each case, six control patients were randomly selected, matched by age, sex, and calendar time (by using the same index date as for cases) and who were current 5-ASA users at the index date. Cases and controls were matched by year of birth, but this age matching criterion was expanded, stepwise, by one year of age, to a maximum of 10 years, if no control was found. Controls with a history of bowel surgery were excluded. Cases and controls were classified according to regularity of use. Two definitions for regularity of 5-ASA use were applied. The first definition was based on the use of six or more 5-ASA prescriptions within 12 months before the index date and the second on the use of six or more 5-ASA prescriptions in the 1224 months before. Type of 5-ASA was classified according to the last prescription issued prior to the index date. Patients receiving more than one type of 5-ASA in the database records were classified as users of other 5-ASA type.

\section{Statistical analysis}

In the cohort analysis, age and sex adjusted relative rates (RR) were estimated using Poisson regression models. In the case control analysis, the odds ratio (OR) of CRC was calculated comparing cases and controls using conditional logistic regression models. The analysis was controlled for clinical variables and drug use that have been associated with the risk of CRC. These included body mass index and history of colon or rectal polyps. Prescriptions for non-steroidal antiinflammatory drugs (NSAIDs), paracetamol, aspirin, oral and rectal glucocorticoids, and immunosuppressants (azathioprine, methotrexate, or ciclosporin) in the six months prior to the index date were also ascertained. Furthermore, the analysis was adjusted for IBD duration (based on the time between the index date and the first record of IBD or 5-ASA prescription, whichever date came first). Hospitalisations for a gastrointestinal disorder and a general practitioner recorded colonoscopy in the 6-24 months before the index date were also noted. Severity of IBD was assessed by considering the number of general practitioner visits/records for IBD symptoms (previous history of diarrhoea, abdominal pain, anaemia, rectal bleeding, weight loss, or constipation in the 6-24 months prior to the index date).

\section{RESULTS}

A total of 33905 patients in the GPRD population had received a 5-ASA prescription: 18969 were assigned to the "5-ASA/IBD" group (56 patients with a history of CRC prior

Table 1 Incidence rates of colorectal cancer (CRC) in the different study cohorts (number of cases per 100 patients per year)

\begin{tabular}{|c|c|c|c|c|c|c|c|c|c|}
\hline \multirow[b]{2}{*}{ Characteristic } & \multicolumn{3}{|c|}{ 5-ASA IBD cohort } & \multicolumn{3}{|c|}{ Sulfasalazine RA cohort } & \multicolumn{3}{|c|}{ Reference cohort (no 5-ASA use or IBD) } \\
\hline & $\begin{array}{l}\text { No of } \\
\text { cases }\end{array}$ & Rate & $\begin{array}{l}\text { Age/sex adjusted } \\
\text { RR }(95 \% \mathrm{Cl})\end{array}$ & $\begin{array}{l}\text { No of } \\
\text { cases }\end{array}$ & Rate & $\begin{array}{l}\text { Age/sex adjusted } \\
\text { RR }(95 \% \mathrm{CI})\end{array}$ & $\begin{array}{l}\text { No of } \\
\text { cases }\end{array}$ & Rate & $\begin{array}{l}\text { Age/sex adjusted } \\
\text { RR }(95 \% \mathrm{Cl})\end{array}$ \\
\hline Overall & 124 & 0.17 & $1.99(1.54-2.56)$ & 69 & 0.12 & $1.26(0.94-1.70)$ & 116 & 0.09 & Reference \\
\hline \multicolumn{10}{|l|}{ Age (y) } \\
\hline $18-34$ & 7 & 0.04 & & 1 & 0.01 & & 1 & $<0.01$ & \\
\hline $35-49$ & 29 & 0.12 & & 7 & 0.05 & & 6 & 0.02 & \\
\hline $50-64$ & 39 & 0.22 & & 12 & 0.06 & & 35 & 0.10 & \\
\hline $65-79$ & 38 & 0.30 & & 39 & 0.27 & & 58 & 0.21 & \\
\hline $80+$ & 11 & 0.49 & & 10 & 0.61 & & 16 & 0.37 & \\
\hline Women & 55 & 0.14 & & 41 & 0.11 & & 58 & 0.08 & \\
\hline Men & 69 & 0.19 & & 28 & 0.14 & & 58 & 0.11 & \\
\hline
\end{tabular}

5-ASA, 5-aminosalicylate; IBD, inflammatory bowel disease; RA, rheumatoid arthritis; RR $(95 \% \mathrm{Cl})$, relative risk (95\% confidence interval). 


\begin{tabular}{|c|c|c|c|}
\hline Characteristic & $\begin{array}{l}\text { Cases } \\
(n=100)\end{array}$ & $\begin{array}{l}\text { Controls } \\
(n=600)\end{array}$ & $\begin{array}{l}\text { Crude OR } \\
(95 \% \mathrm{Cl})\end{array}$ \\
\hline Mean age (y) & 62.9 & 62.7 & \\
\hline Female sex & $42(42.0 \%)$ & $252(42.0 \%)$ & \\
\hline \multicolumn{4}{|l|}{ Body mass index* } \\
\hline$<20$ & 6 & 22 & $1.76(0.66-4.71)$ \\
\hline$\geqslant 26$ & 21 & 167 & $0.78(0.44-1.39)$ \\
\hline \multicolumn{4}{|l|}{ Drug use 6 months before } \\
\hline NSAIDs & 9 & 66 & $0.80(0.38-1.66)$ \\
\hline Aspirin & 9 & 37 & $1.52(0.70-3.28)$ \\
\hline Oral glucocorticoids & 33 & 124 & $1.83(1.17-2.88)$ \\
\hline Immunosuppressants & 3 & 21 & $0.85(0.25-2.94)$ \\
\hline \multicolumn{4}{|l|}{ Medical history } \\
\hline Colon/rectum polyps & 9 & 6 & $10.24(3.42-30.69)$ \\
\hline Colonoscopy 6-24 months before & 13 & 75 & $1.05(0.55-2.01)$ \\
\hline Prior GI hospitalisation 6-24 months before & 13 & 48 & $1.69(0.89-3.20)$ \\
\hline \multicolumn{4}{|l|}{ No of GP visits for IBD symptoms 6-24 months before } \\
\hline 1 & 24 & 138 & $1.24(0.74-2.06)$ \\
\hline $2+$ or more & 18 & 49 & $2.70(1.45-5.04)$ \\
\hline $\begin{array}{l}\text { Mean duration of follow up (y) prior to index date } \\
\text { in GPRD }\end{array}$ & 4.5 & 4.3 & \\
\hline $\begin{array}{l}{ }^{*} \text { Compared with patients with body mass index } \geqslant 20 \text { and } \\
\text { NSAIDs, non-steroidal anti-inflammatory drugs; } G 1 \text {, gastro } \\
\text { General Practice Research Database; GP, general practitior }\end{array}$ & $\begin{array}{l}\text { 26; body mas } \\
\text { testinal; IBD, } \\
\text { ar; OR } 195 \% \mathrm{C}\end{array}$ & $\begin{array}{l}\text { s index missing } \\
\text { flammatory bo }\end{array}$ & $\begin{array}{l}\text { for } 207 \text { patients. } \\
\text { vel disease; GPRD, } \\
\% \text { confidence interval). }\end{array}$ \\
\hline
\end{tabular}

to the first recorded ASA prescription were excluded). Mean age of these patients was 48 years and $53.0 \%$ were women. They were followed for an average of six years. Their average number of 5-ASA prescriptions during follow up was 19.4 (median 10); these were prescribed for an average of one month of treatment. The distribution of the type of prescribed 5-ASA in the "5-ASA/IBD" group was as follows: mesalazine $(57.9 \%)$, sulfasalazine $(37.2 \%)$, olsalazine $(4.6 \%)$, and balsalazide $(0.4 \%)$. The "sulfasalazine/RA" cohort consisted of 14840 patients (40 patients excluded because of CRC history). Each of these patients was matched to one patient without a record of IBD or 5-ASA use.

The incidence rate in the "5-ASA/IBD" group was 0.17 CRC cases per 100 patients per year in this cohort (table 1).

The rate in the reference cohort (that is, patients without IBD and 5-ASA use) was 0.09 (the age and sex adjusted RR in the "5-ASA/IBD" cohort compared with the reference cohort was 1.99 (95\% confidence interval (CI) 1.54-2.56). The CRC risk of patients in the "sulfasalazine/RA" group was comparable with that of the reference patients.

Among the 124 CRC cases in the "5-ASA/IBD" group, the most frequent CRC locations (based on the codes used by the general practitioner and/or general practitioner comments

Table 3 Risk of colorectal cancer (CRC) and type and duration of inflammatory bowel disease (IBD)

\begin{tabular}{llll}
\hline Characteristic & $\begin{array}{l}\text { Cases } \\
(\mathbf{n}=100)\end{array}$ & $\begin{array}{l}\text { Controls } \\
(\mathbf{n}=600)\end{array}$ & $\begin{array}{l}\text { Crude OR } \\
(95 \% \mathrm{CI})\end{array}$ \\
\hline $\begin{array}{l}\text { Type of IBD* } \\
\text { CD }\end{array}$ & 15 & 117 & $\begin{array}{l}\text { Reference } \\
\text { UC }\end{array}$ \\
$\begin{array}{l}\text { Duration of UC† } \\
\text { 0-2 y }\end{array}$ & 13 & 399 & $2.86(1.22-6.72)$ \\
$2-10 y$ & 23 & 77 & Reference \\
$>10 y$ & 40 & 177 & $1.08(0.52-2.27)$ \\
Duration of CD† & & 145 & $2.12(1.07-4.19)$ \\
$0-2 y$ & 2 & 31 & Reference \\
$2-10 y$ & 5 & 59 & $1.56(0.49-4.93)$ \\
$>10 y$ & 8 & 27 & $3.16(1.15-8.68)$ \\
\hline
\end{tabular}

*Type of IBD was not specified by the general practitioner for a small number of patients.

†Based on the time period between the date of the first IBD recording or 5 -aminosalicylate prescribing and the index date.

UC, ulcerative colitis; CD, Crohn's disease; OR (95\% CI), odds ratio $(95 \%$ confidence interval). recorded in the record) concerned the colon (43 patients), rectum (39), sigmoid (5), rectosigmoid (5), descending colon (1), transverse colon (3), ascending colon (1), and caecum (18). There were nine patients with unspecified bowel carcinoma. All-cause mortality was high among CRC cases in all groups: the one year life table mortality in the " 5 -ASA/ IBD" group was $35.8 \%$ (five year $63.7 \%$ ); this was $41.8 \%$ $(61.7 \%)$ for the cases in the "sulfasalazine/RA" group and $41.3 \%(63.7 \%)$ for the cases in the reference group, respectively. The most frequently recorded cause of death among the CRC cases in the "5-ASA/IBD" group was carcinoma $(91.9 \%)$. Of the 124 CRC cases in the "5-ASA/ IBD" group, 100 were current users of 5-ASA drugs (that is, received a prescription in the six months before). These cases were matched to 600 controls: $96.0 \%$ of the cases were matched by year of birth, sex, and calendar time (and 98.2\% were matched within five years of age).

In this population, significant risk factors for CRC included history of colon/rectum polyps (crude OR 10.24 (95\% CI 3.42$30.69)$ ) and number of general practitioner visits for IBD symptoms (one symptom 1.24 (95\% CI 0.74-2.06); two or more symptoms 2.70 (95\% CI 1.45-5.04)) (table 2).

Current use of NSAIDs was associated with a reduced risk of CRC but this did not reach statistical significance (OR 0.80 (95\% CI 0.38-1.66)). Duration and type of IBD also predicted the risk of CRC (table 3 ).

Patients with UC had higher a CRC risk compared with patients with CD (OR 2.86 (95\% CI 1.22-6.72)). In both CD and UC, longer disease duration increased the risk of CRC.

Table 4 shows the risks of CRC according to regularity of 5-ASA use.

Patients who were regular 5-ASA users in the year preceding the index date had a decreased risk of CRC compared with irregular users (crude OR 0.67 (95\% CI 0.441.03); adjusted OR $0.60 \quad$ (95\% CI $0.38-0.96)$ ). Similar reductions in CRC risk were seen when looking at 5-ASA use in the 1-2 years prior to the index date. Regular users of mesalazine appeared to have larger CRC risk reductions than regular users of sulfasalazine but IBD duration was longer among users of sulfasalazine compared with mesalazine (average of 14 and 6 years, respectively). When stratified by disease type, regular 5-ASA users with UC had an adjusted OR for cancer of 0.65 (95\% CI 0.37-1.14) compared with irregular users. For CD, numbers were small but regular users 
Table 4 Regular 5-aminosalicylate (5-ASA) use in the year before and risk of colorectal cancer (CRC)

\begin{tabular}{|c|c|c|c|c|}
\hline Use of 5-ASA & $\begin{array}{l}\text { No of cases } \\
(n=100)\end{array}$ & $\begin{array}{l}\text { No of controls } \\
(n=600)\end{array}$ & $\begin{array}{l}\text { Crude OR } \\
(95 \% \mathrm{Cl})\end{array}$ & $\begin{array}{l}\text { Adjusted OR* } \\
(95 \% \mathrm{CI})\end{array}$ \\
\hline Irregular use 0-12 months before & 54 & 265 & Reference & Reference \\
\hline Regular use 0-12 months before & 46 & 335 & $0.67(0.44-1.03)$ & $0.60(0.38-0.96)$ \\
\hline Sulfasalazine & 22 & 137 & $0.77(0.45-1.34)$ & $0.67(0.36-1.25)$ \\
\hline 6-12 Rx before & 3 & 12 & $1.30(0.35-4.80)$ & $0.95(0.22-4.11)$ \\
\hline 13-30 Rx before & 5 & 53 & $0.45(0.17-1.23)$ & $0.41(0.14-1.20)$ \\
\hline$>30 \mathrm{Rx}$ before & 14 & 72 & $0.91(0.47-1.75)$ & $0.77(0.37-1.60)$ \\
\hline Daily dose $<2$ g & 6 & 32 & $0.93(0.36-2.38)$ & $0.84(0.29-2.42)$ \\
\hline Daily dose $\geqslant 2$ g & 15 & 93 & $0.81(0.43-1.51)$ & $0.69(0.35-1.37)$ \\
\hline Mesalazine & 20 & 186 & $0.51(0.30-0.89)$ & $0.48(0.27-0.88)$ \\
\hline 6-12 Rx before & 10 & 44 & $1.15(0.54-2.44)$ & $1.13(0.49-2.59)$ \\
\hline 13-30 Rx before & 5 & 71 & $0.34(0.13-0.88)$ & $0.30(0.11-0.83)$ \\
\hline$>30 \mathrm{Rx}$ before & 5 & 71 & $0.32(0.12-0.83)$ & $0.31(0.11-0.84)$ \\
\hline Daily dose $<1.2 \mathrm{~g}$ & 1 & 15 & $0.32(0.04-2.51)$ & $0.28(0.03-2.27)$ \\
\hline Daily dose $\geqslant 1.2 \mathrm{~g}$ & 19 & 155 & $0.59(0.34-1.05)$ & $0.56(0.31-1.03)$ \\
\hline Other 5-ASA type & 4 & 12 & $1.74(0.55-5.56)$ & $1.38(0.37-5.08)$ \\
\hline No use $12-24$ months before $†$ & 20 & 86 & Reference & Reference \\
\hline Irregular use 12-24 months before & 31 & 183 & $0.75(0.40-1.40)$ & $0.70(0.35-1.41)$ \\
\hline Regular use $12-24$ months before & 35 & 280 & $0.54(0.30-0.97)$ & $0.51(0.26-0.99)$ \\
\hline
\end{tabular}

*Adjusted odds ratios (ORs) are based on multivariate logistic regression models including body mass index, duration of inflammatory bowel disease (IBD), history of colorectal polyps, use of non-steroidal anti-inflammatory drugs, paracetamol, aspirin, immunosuppressants, oral and rectal glucocorticoids, prior gastrointestinal hospitalisation, recorded colonoscopy, and number of general practitioner visits for IBD symptoms 6-24 months before.

†65 patients had less than two years of retrospective information prior to the index date and were included separately into the model.

$\ddagger$ Total number of 5-ASA prescriptions given at any time before the index date.

Based on the prescribed daily dose of the last 5-ASA prescription recorded prior to the index date.

$95 \% \mathrm{Cl}, 95 \%$ confidence interval.

had an adjusted OR of $1.66(0.29-9.52)$ compared with irregular 5-ASA users.

Among the control patients, regular and irregular users were statistically comparable with respect to prior IBD duration, one year mortality, and number of general practitioner records and barium examinations/colonoscopies in the 6-24 months before (both for regular users in the year before and in the 1-2 years before);

Among 5-ASA users who also had used oral glucocorticoids or immunosuppressants in the six months before, there were no differences in risk of CRC between regular and irregular 5-ASA users (adjusted OR 1.21 (95\% CI 0.43-3.45)). In contrast, regular 5-ASA use was associated with a reduced risk of CRC in non-users of oral glucocorticoids or immunosuppressants (adjusted OR 0.53 (95\% CI $0.30-0.92)$ ). A separate case control analysis was conducted to compare regular and irregular users of oral glucocorticoids or immunosuppressants with IBD. Among users of these antiinflammatory drugs, regular use was also associated with a reduced risk of CRC compared with irregular use (crude OR 0.51 (95\% CI 0.27-0.98); adjusted OR 0.38 (95\% 0.18-0.80)). In patients with RA with current use of sulfasalazine, there were no differences in the risk of CRC between regular and irregular users (crude OR 1.00 (95\% CI 0.38-2.64)). However, the number of cases was small $(n=17)$.

Additional analyses were conducted to evaluate the robustness of the findings. Restriction of the analysis to cases $(n=74)$ and controls $(n=401)$ with $>2$ years of retrospective information prior to the index date yielded comparable results (adjusted OR for regular use in the year before of 0.60 (95\% CI $0.35-1.06$ ) and 0.57 (95\% CI 0.28 1.16) for regular use in the $1-2$ years before. An analysis excluding 5-ASA users who only received one 5-ASA prescription yielded an adjusted OR of 0.68 (95\% CI $0.42-$ 1.11) for regular use in the year before. Medical records were also reviewed for general practitioner visits for CRC symptoms prior to the index date and an analysis was conducted using this revised index date: the adjusted OR for regular use in the year before of 0.63 (95\% CI $0.39-1.01)$ and 0.49 (95\% CI 0.24-0.98) for regular use in the $1-2$ years before. An analysis including all 124 CRC cases found that CRC risk was reduced in patients using 5-ASA regularly compared with irregular/non-users (adjusted OR was 0.68 (95\% CI $0.44-$ 1.06) for regular 5-ASA use in the one year before, and 0.57 (95\% CI $0.36-0.90)$ for regular use in the $12-24$ months before).

We also sent a questionnaire to general practitioners to confirm the CRC diagnosis of 23 cases (the number of cases available for validation was limited due to large numbers of patients who had died; the notes are no longer available for these patients). Twenty returned questionnaires were analysed: the diagnosis of CRC was confirmed by the general practitioner in all of these cases. IBD location was provided in 14 cases: pancolitis UC six, rectum only UC three, descending colon UC two, caecum only UC one, beyond splenic flexure but not pancolitis UC one, and colon and small bowel CD one patient.

\section{DISCUSSION}

We found, as expected, that patients with IBD had an increased risk of CRC, with higher risks in those with longer disease duration. We also found that patients who regularly used a 5-ASA or immunosuppressants had a lower risk of CRC compared with irregular users.

A major concern with case control evaluations of therapy is that they are open to various biases, particularly selection biases. Specifically compliant patients who are regular 5-ASA users are likely to attend their physicians more regularly and comply with other aspects of treatment that might reduce their CRC cancer risk. In this respect it is notable that in the frequently cited study by Eaden et al, visiting a hospital doctor more than twice a year was associated with an $84 \%$ reduction in CRC risk compared with a $75 \%$ reduction with regular 5-ASA therapy. ${ }^{6}$ By nesting our study within a cohort of patients with at least one 5-ASA prescription in the previous 12 months, we hoped to minimise this bias. A second 
Table 5 Case control studies of 5-aminosalicylate (5-ASA) therapy and risk of colorectal cancer in inflammatory bowel disease (IBD)

\begin{tabular}{|c|c|c|c|c|}
\hline Reference & Place & $\begin{array}{l}\text { Cancer } \\
\text { cases }\end{array}$ & $\begin{array}{l}\text { Adjusted OR }(95 \% \mathrm{Cl}) \\
\text { for risk of cancer }\end{array}$ & Comments \\
\hline Pinczowski $1994^{7}$ & Uppsala, Sweden & 102 & $0.38(0.20-0.69)$ & $\begin{array}{l}\text { Only possible to dichotomise SASP use into }<\text { or }>3 \text { month } \\
\text { use }\end{array}$ \\
\hline Eaden $2000^{6}$ & England and Wales & 102 & $0.25(0.13-0.48)$ & Controls all attenders at one clinic \\
\hline Bernstein $2003^{12}$ & Manitoba & 25 & $1.46(0.58-3.73)$ & 5-ASA use within 2 y of CRC \\
\hline Rutter $2004^{13}$ & London & $68^{*}$ & $1.58(0.71-3.51) \dagger$ & SASP use for $>10 y$ \\
\hline Terdiman $2005^{25}$ & US & 364 & $\begin{array}{l}0.65(0.26-1.62) \dagger \\
0.72(0.50-1.05)\end{array}$ & $\begin{array}{l}\text { Other } 5 \text {-ASA use for }>10 y \\
>5 \text { prescriptions of } 5 \text {-ASA } v \text { none in the year preceding } \\
\text { CRC }\end{array}$ \\
\hline Velayos $2005^{26}$ & Mayo, US & 188 & $0.60(0.30-1.21)$ & $>10$ y 5 -ASA therapy $v<1$ y at time of CRC diagnosis \\
\hline This study 2005 & England and Wales & 100 & $0.60(0.38-0.96)$ & Regular $v$ irregular 5 -ASA use in 1 y preceding CRC \\
\hline
\end{tabular}

concern is the source and recording of the drug data. A strength of the GPRD is that prescribing in primary care is recorded prospectively at the time a prescription is issued. While some hospital prescribing of acute treatments will not be captured, this should not affect long term maintenance treatments such as 5-ASAs.

A further strength of this study was that it was a large population based study with near complete collection of significant medical events. This allowed reasonable estimates of the incidence of CRC in 5-ASA users in an unselected population in routine clinical practice. The estimated prevalence of CD and UC in the GPRD population was found to be comparable with those reported in other UK studies. ${ }^{16} 19$ Also, the incidence of CRC in this study of 0.2 cases per 100 patients was broadly comparable with that reported in the recent meta-analysis of cancer risk in IBD which estimated that the overall annual incidence of CRC in UC was 0.3 cases per 100 patients. ${ }^{1}$ However, a direct comparison with the results from the meta-analysis by Eaden et al has limitations given the possible effects of regular 5-ASA therapy or other differences in medical practice. ${ }^{1}$

None the less our study had several limitations. The main limitation was that patients were not randomised to treatment and therefore interpretation as to causation needs to be made with caution. While patients could have reduced risks of CRC as a result of greater compliance rather than their 5-ASA use, they may also be attending more frequently for CRC surveillance. If so, this would lead to a higher likelihood of CRC diagnosis among regular 5-ASA users and hence underestimate any effect of regular 5-ASA use. Our data do not support the presence of this bias: the one year mortality following CRC was comparable among regular and irregular 5-ASA users, as were the number of colonoscopies and general practitioner contacts in the 6-24 months before the case's cancer diagnosis. But given the observational nature of this study, there remains the possibility of confounding by unmeasured characteristics. Another limitation of this study was that we did not have data on lifetime 5-ASA use although exposure characteristics are likely to correlate over time. We found a good concordance between regular use in the one year before and the preceding years. Lastly, we did not have detailed data on the extent of IBD in the cases and controls.

We found that mesalazine was associated with a greater reduction in risk of CRC than sulfasalazine, a finding similar to that of Eaden et al in their UK study. ${ }^{6}$ A possible explanation for this could be that in patients taking sulfasalazine, which is a competitive inhibitor of folate absorption, the anti-inflammatory effect is outweighed by the effect of folate deficiency, which has been independently associated with dysplasia development. ${ }^{20}$ However, as duration of IBD is a strong risk factor for CRC, and as sulfasalazine users had a longer mean duration of IBD than mesalazine users, direct comparison of sulfasalazine and mesalazine in this study is difficult. Like Eaden and colleagues, ${ }^{6}$ we found no major difference in the risk of CRC with recent daily dose of 5-ASA. However, the relationship between daily dose and CRC risk is difficult to assess as the daily dose of a 5-ASA is unlikely to be constant over the many years that most patients take these drugs.

There are different mechanisms by which 5-ASA may reduce the risk of CRC. ${ }^{3}$ There may be direct effects of 5-ASA on mucosal neoplasia, including possible antioxidant, antiproliferative, or proapoptotic effects. ${ }^{3}$ 5-ASA has structural similarities to aspirin and there is now substantial evidence that regular use of aspirin and other NSAIDs reduces the risk of $\mathrm{CRC}^{21}$ with three recent randomised trials showing that aspirin can prevent colorectal adenoma recurrence. ${ }^{22-24}$ But an effect of 5-ASA therapy could also be mediated by the reduction in mucosal inflammation, as chronic or repeated episodes of mucosal inflammation may result in carcinogenesis. ${ }^{3}$ A recent study found that severity of colonic inflammation was an important determinant of the risk of colorectal neoplasia in patients with longstanding UC. ${ }^{13}$ It also found that both non-sulfasalazine 5-ASA drugs and azathioprine showed a trend towards reduced risk of colorectal neoplasia and this finding is similar to ours, with reduced risks of CRC among regular users of mesalazine, oral glucocorticoids, or immunosuppressants. This suggests that long term prevention or reduction in inflammation is the key process in preventing CRC development in IBD.

While a randomised clinical trial would clearly be the most reliable method of assessing the effects of 5-ASA therapy on CRC risk, the long duration required for such a trial and the ethical difficulty of withholding active treatment from the control group make such a trial an impossibility. One therefore has to rely on observational and laboratory based studies of 5-ASA therapy to offer the best evidence. There are a substantial number of laboratory based studies to support the concept that 5-ASA therapy could reduce CRC risk. At present the observational data essentially consists of case control studies. Of the studies so far published (table 5) all have had significant limitations in terms of their size, choice of controls, or assessment of 5-ASA exposure.

A further two case control studies have so far only been reported as abstracts. ${ }^{25}$ Nevertheless, they are all consistent with regular 5-ASA use being associated with a modest reduction in CRC risk of between one third and a half in IBD patients. 


\section{ACKNOWLEDGEMENTS}

Procter and Gamble Pharmaceuticals funded the study.

Conflict of interest: declared (the declaration can be viewed on the Gut website at http://www.gutjil.com/ supplemental).

\section{Authors' affiliations}

T P van Staa, Department of Pharmacoepidemiology and Pharmacotherapy, University of Utrecht, , Utrecht, the Netherlands, and Procter and Gamble Pharmaceuticals, Egham, UK

T Card, R F Logan, Division of Epidemiology and Public Health, University of Nottingham Medical School, Nottingham, UK H G M Leufkens, Department of Pharmacoepidemiology and Pharmacotherapy, University of Utrecht, Utrecht, the Netherlands

\section{REFERENCES}

1 Eaden JA, Abrams KR, Mayberry JF. The risk of colorectal cancer in ulcerative colitis: a meta-analysis. Gut 2001;48:526-35.

2 Bernstein CN, Blanchard JF, Kliewer E, et al. Cancer risk in patients with inflammatory bowel disease: a population-based study. Cancer 2001;91:854-62

3 Bernstein CN, Eaden J, Steinhart AH, et al. Cancer prevention in inflammatory bowel disease and the chemoprophylactic potential of 5-aminosalicylic acid. Inflamm Bowel Dis 2002;8:356-61.

4 Ryan BM, Russel MG, Langholz E, et al. Aminosalicylates and colorectal cancer in IBD: a not-so bitter pill to swallow. Am J Gastroenterol 2003;98:1682-7

5 Eaden J. Review article: the data supporting a role for aminosalicylates in the chemoprevention of colorectal cancer in patients with inflammatory bowel disease. Aliment Pharmacol Ther 2003:18(suppl 2):15-21.

6 Eaden J, Abrams K, Ekbom A, et al. Colorectal cancer prevention in ulcerative colitis: a case-control study. Aliment Pharmacol Ther 2000;14:145-53.

7 Pinczowski D, Ekbom A, Baron J, et al. Risk factors for colorectal cancer in patients with ulcerative colitis: a case-control study. Gastroenterology 1994; 107:117-20.

8 Moody GA, Jayanthi V, Probert CS, et al. Long-term therapy with sulphasalazine protects against colorectal cancer in ulcerative colitis: a retrospective study of colorectal cancer risk and compliance with treatment in Leicestershire. Eur J Gastroenterol Hepatol 1996:8:1179-83.

9 Lindberg BU, Broome U, Persson B. Proximal colorectal dysplasia or cancer in ulcerative colitis. The impact of primary sclerosing cholangitis and sulfasalazine: results from a 20-year surveillance study, Dis Colon Rectum $2001 ; 44: 77-85$
10 Bus PJ, Nagtegaal ID, Verspaget HW, et al. Mesalazine-induced apoptosis of colorectal cancer: on the verge of a new chemopreventive era? Aliment Pharmacol Ther 1999;13:1397-402.

11 Reinacher-Schick A, Seidensticker F, Petrasch S, et al. Mesalazine changes apoptosis and proliferation in normal mucosa of patients with sporadic polyps of the large bowel. Endoscopy 2000;32:245-54

12 Bernstein CN, Blanchard JF, Metge C, et al. Does the use of 5aminosalicylates in inflammatory bowel disease prevent the development of colorectal cancer? Am J Gastroenterol 2003;98:2784-8.

13 Rutter M, Saunders B, Wilkinson K, et al. Severity of inflammation is a risk factor for colorectal neoplasia in ulcerative colitis. Gastroenterology 2004;126:451-9.

14 Walley T, Mantgani A. The UK General Practice Research Database. Lancet 1997;350:1097-9.

15 van Staa TP, Abenhaim L. The quality of information recorded on a UK database of primary care records: a study of hospitalization due to hypoglycemia and other conditions. Pharmacoepidemiol Drug Saf 1994;3:15-21

16 Lewis JD, Brensinger C, Bilker WB, et al. Validity and completeness of the general practice research database for studies of inflammatory bowel disease. Pharmacoepidemiol Drug Saf 2002;11:211-18.

17 van Staa TP, Cooper C, Samuels Brusse L, et al. Inflammatory bowel disease and the risk of fracture. Gastroenterology 2003;215:1591.

18 British National Formulary No 44 (September 2002). London: British Medical Association and the Royal Pharmaceutical Society of Great Britain Wallingford, England, 2002.

19 Rubin GP, Hungin AP, Kelly PJ, et al. Inflammatory bowel disease: epidemiology and management in an English general practice population. Aliment Pharmacol Ther 2000;14:1553-9.

20 Lashner BA, Heidenreich PA, Su GL, et al. Effect of folate supplementation on the incidence of dysplasia cancer in chronic ulcerative colitis. A case-control study. Gastroenterology 1989;97:255-9.

21 Huls G, Koornstra JJ, Kleibeuker JH. Non-steroidal anti-inflammatory drugs and molecular carcinogenesis of colorectal carcinoma. Lancet 2003:362:230-2.

22 Baron JA, Cole BF, Sandler RS, et al. A randomized trial of aspirin to prevent colorectal adenomas. N Engl J Med 2003;348:891-9.

23 Sandler RS, Halabi S, Baron JA, et al. A randomized trial of aspirin to prevent colorectal adenomas in patients with previous colorectal cancer. N Engl J Med 2003;348:883-90.

24 Benamouzig R, Deyra J, Martin A, for The Association Pour La Prevention Par L'Aspirine Du Cancer Colorectal Study Group, et al. Daily soluble aspirin and prevention of colorectal adenoma recurrence: one-year results of the APACC Trial. Gastroenterology 2003;125:328-36.

25 Terdiman JP, Ullman TA, Blumentals WA, et al. A case-control study of 5aminosalicylic acid therapy in the prevention of colitis-related colorectal cancer. Gastroenterology 2005; 128(suppl 2):A299.

26 Velayos FS, Loftus EV Jr, Jess T, et al. A case-control study of predictive and protective factors in 188 patients with colorectal cancer and ulcerative colitis. Gastroenterology 2005;128(suppl 2):A328.

\section{bmjupdates+}

bmjupdates+ is a unique and free alerting service, designed to keep you up to date with the medical literature that is truly important to your practice.

bmjupdates+ will alert you to important new research and will provide you with the best new evidence concerning important advances in health care, tailored to your medical interests and time demands.

Where does the information come from?

bmjupdates+ applies an expert critical appraisal filter to over 100 top medical journals A panel of over 2000 physicians find the few 'must read' studies for each area of clinical interest

Sign up to receive your tailored email alerts, searching access and more...

www.bmjupdates.com 